\title{
Zika vírus: conhecimentos, percepções, e práticas de cuidados de gestantes infectadas
}

\author{
Zikavirus: knowledge, perceptions, and care practices of infected pregnant women \\ Zika virus: conocimientos, percepciones, y prácticas de cuidados de gestantes infectados \\ Camila Alves de Sousa ${ }^{a}$ \\ Daniela do Carmo Oliveira Mendes ${ }^{a}$ \\ Leandro Felipe Mufato ${ }^{a}$ \\ Pollyanna de Siqueira Queirós ${ }^{\mathrm{a}}$
}

\section{Como citar este artigo:}

Sousa CA, Mendes DCO, Mufato LF, Queirós OS. Zika vírus: conhecimentos, percepções, e práticas de cuidados de gestantes infectadas. Rev Gaúcha Enferm. 2018;39:e20180025. doi: https://doi. org/10.1590/1983-1447.2018.20180025
Universidade do Estado de Mato Grosso (UNEMAT), Campus de Tangará da Serra, Departamento de Enfermagem. Tangará da Serra, Mato Grosso, Brasil.
RESUMO

Objetivo: Compreender os conhecimentos, as percepções e as práticas de cuidados de mulheres que contraíram o Zika vírus na gestação.

Métodos: Estudo qualitativo, descritivo-exploratório. A coleta de dados ocorreu com 10 mulheres que contraíram o Zika vírus na gestação, através de entrevista aberta, em um município da Região Centro-0este, Brasil, em 2017. A análise de conteúdo temática permitiu apresentar duas categorias. 0 estudo respeitou os aspectos éticos para as pesquisas com seres humanos.

Resultados: 0 conhecimento das gestantes infectadas se mostrou reduzido a poucas informações, sendo a fonte das informações a internet e a televisão, com pouca expressão dos serviços de saúde. Medo e a preocupação com o bebê estão presentes nos sentimentos influenciando as práticas de cuidado no período da gestação.

Conclusão: As gestantes recebem poucas informações dos serviços de saúde e suas práticas de prevenção se relacionam com o medo de transmitir a infecção para o bebê durante a gestação.

Palavras-chave: Zika vírus. Aedes. Infecção. Gestantes. Cuidado pré-natal. Microcefalia.

\section{ABSTRACT}

Objective: To understand the knowledge, perceptions and care practices of women who have contracted the Zika virus during pregnancy.

Methods: Qualitative, descriptive-exploratory study. The data collection was carried out with 10 women who contracted the Zika virus during pregnancy, through an open interview in a municipality of the Central-West Region, Brazil, in 2017. The analysis of the thematic content allowed to present two categories. The study respected the ethical aspects for research with human beings.

Results: The knowledge of infected pregnant women was reduced to little information, being the source of the information the Internet and the television, with little expression of the health services. Fear and concern about the baby are present in the feelings influencing the care practices in the gestation period.

Conclusion: Pregnant women receive little information from the health services and their prevention practices are related to the fear of transmitting the infection to the baby during pregnancy.

Keywords: Zika virus. Aedes. Infection. Pregnant women. Prenatal care. Microcephaly.

\section{RESUMEN}

Objetivo: Comprender los conocimientos, las percepciones y las prácticas de cuidado de las mujeres que contrajeron el Zika virus en la gestación.

Métodos: Estudio cual itativo, descriptivo-exploratorio. Se recolectaron datos de 10 mujeres que contrajeron el Zika virus en la gestación, a través de una entrevista abierta, en un municipio de la Región Centro-0este, Brasil, en 2017. El análisis de contenido temático permitió presentar dos categorías. El estudio respetó los aspectos éticos para las investigaciones con seres humanos.

Resultados: El conocimiento de las gestantes infectadas se mostró reducido a pocas informaciones, siendo la fuente de informaciones internet y la televisión, con poca expresión de los servicios de salud. El miedo y la preocupación con el bebé están presentes en los sentimientos, influenciando las prácticas de cuidado en el período de la gestación.

Conclusión: Las gestantes reciben poca información de los servicios de salud y sus prácticas de prevención se relacionan con el miedo de transmitir la infección al bebé durante la gestación.

Palabras clave: Virus Zika. Aedes. Infección. Mujeres embarazadas. Atención prenatal. Microcefalia. 


\section{—INTRODUÇÃO}

Um surto de infecções pelo Zika vírus na América Latina, em especial no Brasil, atraiu a atenção da população mundial pela hipótese da infecção estar relacionada a danos à gestação e ao aumento do número de recém-nascidos com microcefalia.

O Zika vírus é do gênero dos flavivírus, transmitido pelo mosquito Aedes aegypti, identificado inicialmente em macacos no Uganda no ano de 1947. Em 1952, no Uganda e na República Unida da Tanzânia, o vírus foi identificado em seres humanos ${ }^{(1)}$. No Brasil, foram confirmados os primeiros casos no começo do ano de 2015, em Natal, Rio Grande do Norte e Camaçari, na Bahia ${ }^{(2-3)}$. Posteriormente foram detectados casos nos estados de São Paulo, Alagoas, Maranhão, Pará e Rio de Janeiro, configurando-se como um recente problema de saúde pública ${ }^{(4)}$.

Em novembro de 2015, o Ministério da Saúde do Brasil evidenciou uma possível relação entre a infecção pelo Zika e a microcefalia em recém-nascidos após exames em um bebê, nascido no Ceará. Pesquisas científicas também averiguaram essa temática, como uma investigação no estado de Sergipe, que apontou a existência de uma relação transitória entre a circulação do vírus e a ocorrência de microcefalia nos recém-nascidos ${ }^{(5)}$.

A microcefalia consiste em uma malformação na qual o cérebro não se desenvolve de modo adequado, sendo caracterizada por um perímetro cefálico inferior ao esperado para a idade e sexo do bebê. O Ministério da Saúde orientado pela Organização Mundial de Saúde (OMS) adotou novos parâmetros para mensurar o perímetro cefálico nos casos de microcefalia, ou seja, para meninos a medida é igual ou inferior a 31,9 centímetros e para as meninas igual ou inferior a 31,5 centímetros, medidos ao nascer. Tais orientações ocorreram para padronizar os valores para todos os países, considerando os bebês nascidos com 37 semanas ou mais(6).

A infecção pelo vírus Zika passa a ser listada como doença de notificação compulsória nacional no Brasil. Na nona edição do boletim epidemiológico sobre o Zika foi divulgado o número de casos notificados de microcefalia, sendo que até 21 de maio de 2016 foram notificados 7.343 casos de microcefalia no Brasil, destes 1.431 foram confirmados como microcefalia e/ou alteração do Sistema Nervoso Central ${ }^{(7)}$.

As gestantes no primeiro trimestre de gestação são consideradas população de risco para infecção por Zika vírus, por ser a fase de formação fetal. No segundo trimestre existe o risco de malformação desencadeada pelo vírus, porém em menor grau. A partir do terceiro trimestre os riscos estão reduzidos, visto que o feto encontra-se formado ${ }^{(8)}$.
A infecção por Zika vírus pode afetar todos os grupos etários e ambos os sexos, sendo atualmente conhecida como uma doença febril aguda, que na maioria dos casos leva a uma baixa necessidade de hospitalização, e quando sintomática apresenta febre baixa, exantema, artralgia, mialgia, cefaleia, hiperemia conjuntival e, menos frequentemente, edema, odinofagia, tosse seca e alterações gastrointestinais, principalmente vômitos ${ }^{(9)}$.

Ainda não existe tratamento específico para a infecção, logo as medidas de prevenção são os melhores métodos para redução dos casos, principalmente a proteção contra a picada do mosquito (1). As principais medidas para minimizar a infecção são a erradicação do mosquito e o controle de propagação da doença(10). Cabem, então, aos profissionais de saúde, a educação em saúde da população frente ao Zika vírus, buscando principalmente, o empoderamento da gestante e sua adesão a medidas preventivas, além do desenvolvimento da assistência pré-natal de forma efetiva, já que várias complicações podem ser evidenciadas ainda durante a gestação da mulher.

Considerando o exposto, esta pesquisa busca responder o seguinte questionamento: Quais são os conhecimentos, as percepções e as práticas de cuidados de mulheres que vivenciaram a infecção pelo Zika vírus na gestação? Objetivou-se compreender os conhecimentos, as percepções e as práticas de cuidados de mulheres que contraíram o Zika vírus na gestação.

\section{- MÉTODOS}

Trata-se de uma pesquisa do tipo descritivo-exploratória, de abordagem qualitativa, realizada em um município polo da região médio-norte do Estado de Mato Grosso, Região Centro-Oeste, Brasil, com 10 mulheres que contraíram a infecção pelo Zika vírus na gestação.

Inicialmente, os pesquisadores se dirigiram às Unidades Básicas de Saúde (UBS) do município para um levantamento das mulheres que quando gestantes foram notificadas com a infecção. A busca ativa por sujeitos participantes ocorreu com a pesquisadora principal indo nas unidades de saúde e solicitando a indicação de casos de infecção durante o período gestacional por Zika vírus ao profissional enfermeiro e aos Agentes Comunitários de Saúde de cada unidade. As participantes elegíveis para essa investigação atenderam aos critérios de inclusão: 1) diagnóstico de Zika vírus durante a gestação, independente do trimestre gestacional; 2) ser residente no município local do estudo; 3 ) ser cadastrada em uma unidade básica de saúde do município; 4) ter idade igual ou superior a 18 anos; 5) já ter concluído a experiência da gestação na qual foi diagnosticada 
com a infecção. Previu-se a exclusão daquelas com agravos físicos ou psicológicos que dificultassem sua participação no estudo (no entanto, não houve gestantes excluídas).

Para a elegibilidade do número final de entrevistadas, considerou o critério de saturação dos dados. Este recurso metodológico na investigação qualitativa define o momento de interromper a construção de informações em função da confiança empírica de que o conjunto das informações interpretadas não mais fornecem elementos para nova teorização(11).

Para a coleta de dados realizou-se entrevistas abertas, guiada pelas perguntas norteadoras "O que você sabe sobre o Zika vírus? Onde ou por quem obteve informações sobre o Zika vírus? Conte-me suas experiências, perspectivas e sentimentos ao vivenciar a infecção pelo Zika vírus. Quais as práticas de cuidado que você realiza frente ao Zika vírus?". As entrevistas também permitiram dados de caracterização das participantes, tais como idade, naturalidade, escolaridade, ocupação, renda familiar, estado civil e número de gestações. As entrevistas foram realizadas individualmente, gravadas por meio de registro de áudio (equipamento digital), autorizadas pelas participantes, no período de março a maio de 2017. O local foi escolhido pela participante, ou seja, na unidade de saúde ou em seu domicílio. O diário de campo também foi utilizado para anotações de observações feitas durante os encontros com as mulheres.

O processo de análise das entrevistas se deu concomitante a coleta de dados, visando ao atendimento do critério de saturação dos dados. Todas as entrevistas foram transcritas na íntegra e analisadas conforme a técnica de análise de conteúdo, modalidade temática. A análise temática segue uma trajetória que consiste em: categorização, inferência, descrição e interpretação. A categorização demanda do pesquisador, grande conhecimento em descobrir um plano classificatório adequado. A inferência que é feita quando se deduz de maneira lógica algo do conteúdo que está sendo analisado. A descrição é definida como enumeração das características do texto, resumida após tratamento analítico, e a interpretação é a significação concedida a essas características, que foram enumeradas durante a descrição ${ }^{(12)}$.

Essa investigação é um subprojeto de um projeto matricial aprovado pelo Comitê de Ética em Pesquisa da Universidade do Estado de Mato Grosso (UNEMAT) sob o protocolo de no 1.400.656/2016, respeitando integralmente a resolução 466/2012. Foi apresentado o Termo Consentimento Livre e Esclarecido a todas as participantes desta pesquisa. As mesmas tiveram seu anonimato resguardado sendo identificadas por nome de flores (Exemplo: Jasmim, Orquídea, Rosa, entre outras).

\section{RESULTADOS}

O perfil socioeconômico das participantes da pesquisa mostra que possuíam faixa etária entre 18 a 36 anos de idade, eram predominantemente casadas, pardas, com ensino médio completo, do lar, com renda mensal de um salário mínimo e naturalidade no estado de Mato Grosso. Quanto à paridade, oito mulheres eram multíparas, com número de gestação entre uma a sete e duas eram primíparas. De acordo com os relatos das participantes da pesquisa, nenhum recém-nascido apresentou microcefalia ao nascer.

Após a análise dos dados, emergiram duas categorias: "Infecção por Zika vírus associada à microcefalia: conhecimento fragilizado de gestantes" e "Medo, preocupação e práticas de cuidados de gestantes ao vivenciar a infecção pelo Zika vírus".

\section{Infecção por Zika vírus associada à microcefalia: conhecimento fragilizado de gestantes}

As gestantes expressaram conhecimento limitado quanto à infecção por Zika vírus, associando o vírus somente com a ocorrência de microcefalia em recém-nascidos, e o modo de transmissão pelo vetor Aedes aegypt:

A única coisa que eu sei é o que todo mundo já sabe, que o problema principal é que causa microcefalia em bebês de mulheres grávidas (Bromélia).

Eu sei que dá malformação na criança, no caso na cabeça, nasce com problema né?! E só essa a informação mesmo (Orquídea).

Então eu sei que ela [doença] é transmitida por um mosquito né, o Aedes aegypt (Tulipa).

E quando a orientação era oferecida, esta surgia tardiamente, oferecidas pelo profissional médico. O profissional médico ocupou destaque como fonte exclusiva de informações profissionais sobre a infeção por Zika:

[..., por exemplo, no meu pré-natal o doutor nunca me falou nada [sobre o Zika vírus] (Rosa).

[...] o médico falou para passar repelente e esse cuidado em casa eu não tinha certo, eu passava nas áreas que estava exposta, na blusa eu não passava, no caso ele falou para passar em cima da roupa, aí quando veio esta orientação já era tarde, já tinha acontecido [infecção pelo Zika vírus] (Orquídea). 
Em relação às outras fontes de informação sobre o Zika vírus, predominantemente as mulheres relataram os meios de comunicação em massa dentre eles a internet e suas as redes sociais e a televisão:

Nas redes sociais, na TV, hoje em dia em tudo e qualquer lugar a gente ouve né falar sobre isso [Zika vírus] (Iris).

[...] a gente via mais na televisão, ainda mais lá no nordeste né que a gente assistia esses casos, aí eu ficava vendo, mas depois eu até parei de assistir porque eu fiquei morrendo de medo [...] (Rosa).

\section{Medo, preocupação e práticas de cuidados de gestantes ao vivenciar a infecção pelo Zika vírus}

As gestantes infectadas pelo Zica vírus apresentaram sinais e sintomas caraterísticos da infecção, como exantema, prurido e febre. A partir do quadro clínico decidiram por procurar o serviço de saúde para realizar o exame com vistas a descartar ou confirmar a infecção.

Começou a sair várias manchinhas na minha pele e coceira e, até então eu achei que era alergia e que eu tinha comido alguma coisa e tinha dado reação, mas aí fui ao médico fazer o exame e deu que era Zika (Tulipa).

[...] começou uns carocinhos no meu corpo e febre, mas eu não sabia bem o que era, até porque eu não tinha ouvido falar muito sobre a Zika, meu marido que chegou falando que era para eu ir ao posto [UBS] que talvez fosse a Zika, a partir daí eu já comecei a ficar com medo [...] (Amarílis).

Quando diagnosticadas, houve relato de que a gestante foi encaminhada ao pré-natal de alto risco:

[...] no pré-natal o médico da nossa unidade saúde da família orientou para a gente estar indo para o posto central [centro de especialidades do município onde se realiza pré-natal de alto risco] (Orquídea).

Seguiu-se ao diagnóstico o medo e a preocupação relacionados às consequências dessa infeção, dentre os sentimentos apontados pelas gestantes que vivenciaram a infecção pelo Zika vírus. Referiam-se, principalmente, ao recém-nascido e aos cuidados que deveriam ser adotados após o nascimento do mesmo.

[...] talvez meu filho pudesse vir com microcefalia, então o medo era o que me dominava mais (Tulipa).
[...] medo e preocupação da minha filha nascer com algum problema de saúde (Violeta).

[...] a sensação é a pior possivel, é horrivel porque a gente não sabe se vai passar para o bebê, qual é a consequência, então é muito ruim (Jasmim).

[...] enquanto não vê o rostinho dele [recém-nascido], você fica com medo (lris).

As gestantes também expressaram o medo de não conseguir cuidar do filho de modo adequado, caso tivesse uma alteração:

[...] no caso medo de não conseguir cuidar da criança se ela nascer com alguma malformação. Como eu iria cuidar se nem sabia o que era aquilo direito, ai eu pensava onde poderia estar buscando referência, quem iria cuidar, quem iria orientar as mães, tudo isso passava pela minha cabeça (Orquídea).

Quando eu peguei Zika eu fiquei morrendo de medo, alguns conhecidos falavam assim "ah seu filho vai nascer com uma cabeça pequeninha, como você vai lidar com uma pessoa especial? Você está preparada para ser mãe, para receber uma criança assim?", tudo por causa da Zika (Rosa).

E ainda evidenciaram práticas de cuidados que deveriam ser adotadas na prevenção da infecção pelo Zika vírus, como o uso de repelentes e roupas compridas e os cuidados que impedem a criação e proliferação do vetor:

\section{[...] passar repelente, usar calça, o cuidado para não deixar água parada em casa (Iris).}

[...] repelente, usar roupa comprida, cuidar do quintal, das vasilhas para não ficar com água para o mosquito não criar [...] (Jasmim).

Eu trancava as janelas, até hoje minha janela do quarto não fica aberta, e usava repelentes, passava a noite e passava de dia (Orquídea).

As gestantes relataram o não uso de roupas compridas decorrente do clima quente e úmido do município e que após terem contraído o vírus não praticavam mais os cuidados adotados anteriormente, como o uso de repelentes: 
Eu não usava roupa comprida porque eu não aguentava, é muito calor, eu me sufocava se ficasse com roupa comprida [risos] (Violeta).

Eu usava repelente, eu sempre me cuidava, ai depois que eu peguei a doença eu nem me importei mais sabe?! Não usava mais repelente, até porque eu sentia muito enjoo de qualquer cheiro (Amarílis).

Outro aspecto relatado pelas participantes dessa pesquisa foi à insuficiência das práticas coletivas para o combate dos criadouros do vetor transmissor pela comunidade em geral:

Creio eu, que peguei [infeç̧ão pelo Zika vírus] não foi aquiem casa, acho que eu peguei fora, porque eu trabalhava e saia muito. Onde eu trabalhava doze pessoas pegou e lá no escritório tem muito jardim, então pode ter sido lá (Bromélia).

[...] aqui em casa nunca teve água parada, sempre foi bem limpinho. O duro é que tem um pasto aqui do lado de casa e o povo joga tudo quanto é sujeira [...] (Violeta).

\section{DISCUSSÃO}

O precário conhecimento de gestantes sobre a infecção por Zika vírus já foi retratado na literatura, mesmo em mulheres com maiores níveis de escolaridade e renda, em relação às gestantes que aqui foram entrevistadas ${ }^{(13)}$. $\mathrm{O}$ conhecimento das gestantes que tiveram o diagnóstico de infecção pelo Zika vírus, sobre o vírus em questão e os sintomas que sua infecção causa, se mostrou reduzido a algumas poucas informações que, em sua maior dimensão, são concedidas pela mídia, por meio da internet e pela televisão, também como evidenciado em outro estudo, realizado nos Estados Unidos da América (EUA)(14). Essa característica do conhecimento sobre a infecção por Zika pode ser vista como uma fragilidade relacionada a um déficit de orientações médicas e dos serviços públicos de saúde. Isso porque, as participantes deste estudo são gestantes que realizaram o pré-natal nas unidades básicas de saúde em que eram cadastradas e, portanto, tiveram contato com profissionais de saúde nas consultas de pré-natal.

Chama a atenção que desde o primeiro caso registrado no Brasil, em 2015, até o início da coleta de dados, em 2017, já haviam decorrido dois anos. Nos EUA, foi realizada uma pesquisa sobre o conhecimento e percepções de mulheres em idade reprodutiva sobre o Zika vírus, apenas quatro semanas após terem confirmado casos de transmissão ori- ginários de dentro país (transmissão doméstica) e não de pessoas que viajaram para áreas de risco. Os pesquisadores detectaram que as mulheres em idade reprodutiva, em locais de transmissão do Zika vírus, tinham elevado conhecimento sobre a transmissão da doença, inclusive, sendo alertadas pelo departamento de saúde para adiar a gestação no período. Ademais, as mulheres que eram gestantes conheciam mais sobre transmissão do que as demais muIheres em idade reprodutiva ${ }^{(14)}$. Ressalta-se, que no estudo citado, muitas mulheres, cerca de 30\%, tinham ensino superior, o que difere do perfil de escolaridade das gestantes que aqui foram entrevistadas, que tinham somente o ensino médio completo.

O perfil da população brasileira que utiliza os serviços públicos de saúde também merece ser melhor investigado por novas pesquisas no que diz respeito à receptividade de campanhas de prevenção e medidas de controle em casos de doenças emergentes e surtos. Isso porque, já se constatou que características da população, tais como nível de escolaridade, pode influenciar a forma como uma população específica recebe informações sobre saúde em casos de recomendações sobre prevenção de doenças emergentes ${ }^{(15)}$.

No Brasil, espera-se que a atuação de uma equipe multiprofissional, capacitada para distribuir informações à população, possa influenciar o que as gestantes atendidas em serviços primários de saúde conhecem da infecção por Zika vírus ${ }^{(8)}$. Apesar de que as informações sobre a doença e suas condicionalidades devem ser trabalhadas nas UBS, durante as consultas de pré-natal individuais, ou em ações educativas coletivas, não se pode observar nas falas das gestantes deste estudo, algum conhecimento que fosse além da relação da infecção por Zika com o nascimento de bebês com microcefalia.

Sobre a relação Zika vírus e microcefalia, o Brasil apresentou aumento dos casos de infecção juntamente com a ocorrência de aumento de casos de microcefalia, principalmente na região nordeste do país, o que foi sugestivo de uma associação entre esses dois fatores ${ }^{(5)}$. Com o tempo, a associação entre microcefalia e infecção pelo Zika vírus foi se fortalecendo na literatura nos anos de 2015 e $2016^{(0,16)}$. Essa mescla de eventos do aumento de infecções e da microcefalia ocorreu há apenas dois anos antes da realização deste estudo, o que suscita a dúvida sobre a própria capacidade de dar afirmações concretas sobre a infecção por Zika vírus por parte dos profissionais de saúde, outra situação que pode influenciar na fragilidade de conhecimento das gestantes aqui estudadas. O surto da doença que avançou rapidamente do Brasil para a toda a América requer informações científicas com fortes evidencias, e que essas informações sejam repassadas aos profissionais que 
atendem as populações de risco em todo o território brasileiro, gerando um desafio para o governo.

A falta de evidência científica de que o Zika vírus infectado em gestantes é condição necessariamente associada à microcefalia leva a uma controvérsia na prática da assistência pré-natal. A infecção, em si, pelo vírus, não traria consequências graves a ponto de a gestante precisar de atendimento especializado. Porém, a hipótese de que esta infecção provoca a microcefalia e condições patológicas para o bebê pode ser uma das explicações para que o profissional de saúde da unidade básica de saúde as encaminhe para um tratamento especializado, como exposto pelas gestantes entrevistadas nesta pesquisa. Este achado pode indicar que o medo e preocupação não é um sentimento exclusivo da gestante, mas pode ser dos profissionais também, que procuram resguardo na busca de serviços de maior complexidade para as gestantes infectadas.

O Ministério da Saúde do Brasil ressalta que a escassez de publicações em língua portuguesa estava dificultando a atualização dos profissionais de saúde( ${ }^{(9)}$. Fato esse que possivelmente contribui, em certa medida, para a fragilidade ou ausência das orientações por profissionais na atenção básica em saúde.

Para além da microcefalia como consequência da infecção por Zika, existem publicações internacionais de estudos realizados no Brasil, que mostram que há um risco substancial de desfechos infantis desfavoráveis após a infecção materna ${ }^{(17)}$. Estudo realizado avaliando o conhecimento sobre o Zika vírus nos Emirados Árabes Unidos, verificou que $62,8 \%$ dos entrevistados apresentaram COnhecimento precário da doença. A população do estudo compreendeu estudantes universitários de ciências médicas e da saúde ${ }^{(18)}$. Evidencia-se, então, a importância do fortalecimento da discussão em torno do tema, não apenas entre mulheres infectadas, mas também entre os futuros profissionais de saúde e no meio acadêmico, corresponsáveis pela conscientização a respeito de tais surtos e suas medidas preventivas.

Quanto à fonte do conhecimento nas unidades de saúde, a figura do profissional médico se fez presente nas falas das gestantes entrevistadas para este estudo. Esse dado mostra-se desafiador para os objetivos da Política Nacional de Atenção Básica que procura realizar a assistência básica com a atuação de uma equipe multiprofissional. Dessa forma, pelas falas obtidas aqui, observa-se a figura do médico como única fonte de orientações, mas que não realizou as ações de educação em saúde com vistas à prevenção de doenças. Chama a atenção, no âmbito da equipe multiprofissional da atenção básica, a ausência do profissional enfermeiro, pois este integra a equipe e realiza, também, consultas de pré-natal. Esperar-se-ia que enfermeiros fossem mais uma fonte de orientações sobre a prevenção da infecção por Zika numa época de surto, em que ser gestante gerava uma série de expectativas quanto à infecção pelo vírus, o que não se expressa no presente estudo.

Pode-se ponderar, então, sobre a qualidade das consultas de pré-natal quanto ao diálogo para sanar dúvidas das gestantes sobre a infecção pelo vírus. Haja vista, que as consultas se realizaram numa época em que se ouvia sobre a infecção de modo amplo em meios de comunicação, como a televisão, tornando a infecção um assunto popular. A resposta dos serviços de saúde públicos à um surto, com a capacitação dos profissionais, bem como, a receptividade das recomendações do Ministério da Saúde pela população nestes casos, carece de maiores estudos no Brasil. Recomendações do Centro de Controle e Prevenção de Doenças, nos EUA, apontam que em áreas de risco toda gestante deve ser perguntada sobre a possibilidade de infecção antes e durante a gestação, em todas as consultas de pré-natal(19).

A equipe multiprofissional de saúde vinculada à atenção primária em saúde deve realizar orientações às mulheres em idade fértil, que possuam o desejo de engravidar, sobre a prevenção da infecção pelo Zika vírus durante a gestação. Além disso, é essencial garantir o início precoce do pré-natal, bem como todos os exames laboratoriais e obstétricos, e outros cuidados assistenciais durante as consultas ${ }^{(9)}$.

À época de realização deste estudo, as campanhas informativas promovidas pelos meios de comunicação em massa contribuíam de maneira favorável para a disseminação de conhecimento. Porém, muitas informações midiáticas acabam apresentando o assunto de modo negativo, 0 que favorece falas como as que aqui coletamos, que expressam o sentimento de medo com as informações transmitidas pela televisão. A mídia, internet e televisão, também foi apontada como a principal fonte de informações sobre as infecções por Zika vírus nos EUA, em 2017, com poucas muIheres recebendo informações de dos serviços médicos ${ }^{(14)}$.

No caso das mulheres gestantes participantes deste estudo, as alterações no corpo marcaram o início da necessidade de procurar por atendimento médico, não sendo a infecção por Zika vírus algo esperado por elas, o que pode ser explicado pelo precário conhecimento que tinham sobre a doença, incluindo aí informações sobre os sintomas e medidas de prevenção. Em algumas pessoas a infecção pelo vírus pode ser assintomática e os sintomas quando estão presentes, são normalmente rápidos e autolimitados, sendo os mais frequentes a febre, cefaleia, exantema, olhos vermelhos e dores articulares ${ }^{(1)}$. Como as gestantes não conheciam estas informações, não associaram o mal-estar à infecção por Zika vírus. 
Em um estudo realizado com 60 pessoas em quatro municípios do nordeste brasileiro verificou-se que 100\% dos indivíduos infectados pelo Zika vírus apresentaram exantema, alguns relataram como sintoma principal o prurido e outros, mesmo apresentando prurido, se queixaram de dor articular ${ }^{(20)}$. É importante o reconhecimento dos sintomas e a oferta de exames clínicos pelos serviços de saúde, buscando um diagnóstico mais precoce possível.

Uma vez diagnosticadas, sobressai quanto aos medos e preocupações vivenciadas pelas gestantes infectadas pelo Zika vírus o aparecimento de microcefalia em seu bebê. As próprias informações obtidas na televisão e a ausência de orientações médicas concretas, leva a população, e as gestantes, a conviver com a angústia, medo e a preocupação decorrente da infecção. Destaca-se nos achados deste estudo a preocupação das gestantes em transmitir o vírus para o filho durante a gestação, fundamentado na crença de que o vírus necessariamente provoca má formação e microcefalia. A preocupação com o bebê surgiu de modo muito mais significativo do que preocupações com o próprio bem-estar. Por associarem a infecção com a microcefalia, o medo de não conseguir cuidar de uma criança nesta condição surge durante a gravidez.

O medo da transmissão para o filho, leva ao anseio sobre saber cuidar de um bebê com microcefalia e as gestantes se veem desafiadas quanto aos cuidados que uma criança com microcefalia pode demandar.

No âmbito das medidas preventivas de infecção, observa-se a recomendação do uso contínuo de roupas compridas, telas em janelas e portas, repelentes e mosquiteiros. Além da limpeza dos possíveis criadouros do mosquito - quintais, caixas d'água, vasos de plantas, vasilhas de animais, entre outros. Algumas práticas coletivas devem ser adotadas pela sociedade a fim de contribuir para a redução das doenças causadas pelo Aedes aegypti. Sendo que a melhor forma, apontada também por material teórico internacional, é o controle do vetor, ou seja, eliminar o mosquito, para isto é imprescindível que a população elimine todos os criadouros do mosquito, evitando-se a sua proliferação e propagação da doença ${ }^{(10)}$.

As medidas preventivas tomadas pelas gestantes durante a gestação foram, em parte, abandonadas com o tempo. Sabe-se, contudo, que a reinfecção pelo vírus da dengue, em que o vetor transmissor é o mesmo, aumenta as chances de a doença surgir de forma agravada. Isso mostra que parte da preocupação com o mosquito se dava em decorrência da experiência da gestação e da possível infecção pelo Zika vírus durante este período.

\section{Q CONSIDERAÇÕES FINAIS}

O conhecimento de gestantes frente ao Zika vírus revelou-se fragilizado, possivelmente, associado com a fragilidade de orientações recebidas nas consultas na atenção básica em saúde e nos meios de comunicação em massa, sendo a televisão e a internet as principais fontes de informações sobre Zika vírus e microcefalia. O achado referente ao encaminhamento ao pré-natal alto risco da gestante infectada pelo Zika vírus, infere que há certa controvérsia entre o que se preconiza para pré-natal de alto risco e como estas gestantes são acompanhadas pelos profissionais que as atenderam. Em suas vivências, as entrevistadas evidenciaram os sentimentos de medo e a preocupação com o acometimento da infeção no recém-nascido. E, ainda, relataram práticas de cuidados que deveriam ser adotadas na prevenção da infecção pelo Zika vírus, no entanto, ao contrair a doença, alguns cuidados foram abandonados.

O medo e preocupação de transmissão para o filho são achados importantes deste estudo, pois a literatura sobre o Zika vírus tem se voltado para o conhecimento de mulheres ou aderência de medidas de prevenção, sem relatar as consequências não biológicas para as mulheres infectadas.

Com o surto de Zika vírus em 2015, no Brasil, e depois pelos casos que se espalharam pela América Central e EUA, o conhecimento científico aumentou em torno da etiologia viral e o mecanismo biológico. O desafio de se realizar estudos que não levantem apenas aspectos biológicos e clínicos, mas também da qualidade das consultas de profissionais de saúde em contato com populações de risco e casos de surto de doenças permanece no Brasil.

Uma das limitações encontradas para o desenvolvimento dessa investigação foi a escassez de publicações científicas no que diz respeito a estudos qualitativos que busquem a compreensão de significados e práticas de mulheres diagnosticadas com uma infecção por Zika vírus, visto que as pesquisas que se tem produzido traduzem majoritariamente aspectos clínicos e epidemiológicos da infeção, ou, ainda, estudos sobre conhecimento sem associação com o que uma gestante infectada vivencia, tal como medo e preocupação demonstrados neste estudo.

Uma das contribuições deste estudo é subsidiar os profissionais da atenção básica em saúde na compreensão dos conhecimentos, das percepções e das práticas de cuidados de gestantes ao vivenciar a infecção pelo Zika vírus. Essas informações podem oferecer pistas importantes para ampliação da prática clínica frente ao agravo. Outras contribuições indiretas do estudo seriam o fortalecimento do debate em torno do tema no cenário científico e a melhoria e ampliação das informações sobre práticas de saúde de 
gestantes e profissionais visando um melhor atendimento da população estudada.

Maiores estudos precisam ser realizados sobre como a população é informada e adere às recomendações de prevenção e cuidados nos casos de surtos. Esses conhecimentos podem trazer mais eficácia ao sistema de saúde brasileiro ao atuar com populações de risco em caso de novos surtos de doenças. Sugere-se que novas pesquisas sejam realizadas, em distintas realidades e contextos, explorando as experiências e as práticas de cuidados de mulheres ao se infectarem por Zika vírus durante a gestação.

\section{口 REFERÊNCIAS}

1. Word Health Organization [Internet]. Geneva: WH0; 2016 [cited 2016 Sep 06]. Zika virus; [about 7 screens]. Available from: http://www.who.int/mediacentre/factsheets/zika/en/.

2. Zanluca C, Melo VCA, Mosimann ALP, Santos GIV, Santos CND, Luz K. First report of autochthonous transmission of Zika virus in Brazil. Mem Inst Oswaldo Cruz. 2015;110(4):569-72. doi: https://doi.org/10.1590/0074-02760150192.

3. Campos GS, Bandeira AC, Sardi SI. Zika Virus Outbreak, Bahia, Brazil. Emerg Infect Dis. 2015;21(10):1885-6. doi: https://doi.org/10.3201/eid2110.150847.

4. Vasconcelos PFC. Doença pelo vírus Zika: um novo problema emergente nas Américas? [Editorial]. Rev Pan-Amaz Saude. 2015 [citado 2016 set 20];6(2):9-10. Disponível em: http://scielo.iec.gov.br/scielo.php?script=sci_ arttext\&pid=\$2176-62232015000200001\&lng=pt\&nrm=iso\&tlng=pt.

5. Cabral MC, Nóbrega MEB, Leite PL, Souza MSF, Teixeira DCP, Cavalcante TF, et al. Descrição clínico-epidemiológica dos nascidos vivos com microcefalia no estado de Sergipe, 2015. Epidemiol Serv Saúde. 2017;26(2):245-54. doi: https://doi. org/10.5123/s1679-49742017000200002.

6. Governo do Brasil [Internet]. Brasilia; C2016 [citado 2016 mar 09]. Brasil adota norma da OMS e reduz medida para microcefalia [aprox. 4 telas]. Disponível em: http://www.brasil.gov.br/editoria/saude/2016/03/brasil-adota-normada-oms-e-reduz-medida-para-microcefalia.

7. Organização Pan-Americana de Saúde (BR). Resposta da Representação da OPAS/OMS no Brasil para a epidemia do vírus da Zika e suas consequências. Brasília: OPAS; 2016 [citado 2016 maio 30]. Boletim semanal \#9. Disponivel em: http://www.pahoorg/bra/images/stories/SalaZika/ boletimzika_09_30maio.pdf.

8. Cunha RV, Geniole LAI, Brito CAA, França NPS, Santos Neto OG, Nascimento DDG, et al. Zika: abordagem clínica na atenção básica. Cuiabá: UFMS, Fiocruz; Braślia (DF): Ministério da Saúde, UNA-SUS; 2016 [citado 2017 set 15]. Disponível em: http://www.saude.pi.gov.br/uploads/warning_document/file/276/livro.pdf.
9. Ministério da Saúde (BR). Secretaria de Atenção à Saúde. Protocolo de atenção à saúde e resposta à ocorrência de microcefalia relacionada à infecção pelo vírus Zika. Versão 2.0. Brasilia (DF); 2016 [citado 2017 set 15]. Disponível em: https:// bit.ly/2v3DKM8.

10. Oliveira A, Malinger G, Ximenes R, Szejnfeld P, Alves S, Bispo de Filippis A. Infección intrauterina por virus Zika y microcefalia. Rev Chil Infectol. 2016;33(1):96. doi: https://doi.org/10.4067/S0716-10182016000100018.

11. Minayo MCS. Amostragem e saturação em pesquisa qualitativa: consensos e controvérsias. Rev Pesq Qualit. 2017 [citado 2017 out 12];5(7):1-12. Disponível em: https://editora.sepq.org.br/index.php/rpq/article/view/82/59.

12. Minayo MCS, Deslandes SF, Gomes R. Pesquisa social: teoria método e criatividade. 33. ed. Petrópolis: Vozes; 2013.

13. Mouchtouri VA, Papagiannis D, Katsioulis A, Rachiotis G, Dafopoulos K, Hadjichristodoulou C. Knowledge, attitudes, and practices about the prevention of mosquito bites and Zika virus disease in pregnant women in Greece. Int J Environ Res Public Health. 2017; 14(4):367. doi: https://doi.org/10.3390/ijerph14040367.

14. Curry CL, Tse C, Billero V, Hellerstein L, Messore M, Fein L. Knowledge and perceptions of Zika virus among reproductive-aged women after public announcement of local mosquito-borne transmission. J Obstet Gynaecol Res. 2017;44(3):503-8. doi: https://doi.org/10.1111/jog.13533.

15. Piltch-Loeb R, Abramson DM, Merdjanoff AA. Risk salience of a novel virus: US population risk perception, knowledge, and receptivity to public health interventions regarding the Zika virus prior to local transmission. PLoS One. 12(12):e0188666. doi: https://doi.org/10.1371/journal.pone.0188666.

16. Rasmussen S, Jamieson D, Honein MA, Petersen LR. Zika virus and birth defects: reviewing the evidence for causality. N Engl J Med. 2016;374(20):1981-7. doi: https://doi.org/10.1056/NEJMsr1604338.

17. Brasil P, Pereira JP, Moreira E, Nogueira RMR, Damasceno L, Wakimoto M, et al. Zika virus infection in pregnant women in Rio de Janeiro. N Engl J Med. 2016;375(24):2321-34. doi: https://doi.org/10.1056/NEJMoa1602412.

18. Rabbani SA, Mustafa F, Shougair T, Mohamad I, Tahsin N. Zika virus disease knowledge among the future health-care providers of the United Arab Emirates. J Adv Pharm Technol Res. 2018;9(1):20-5. doi: https://doi.org/10.4103/japtr. JAPTR_239_17.

19. Oduyebo T, Polen KD, Walke HT, Steiner SR, Lathrop E, Rabe IB, et al. Update: interim guidance for health care providers caring for pregnant women with possible Zika virus exposure - United States (including U.S. Territories), July 2017. MMWR Morb Mortal Wkly Rep. 2017;66(29):781-93. doi: https://doi. org/10.15585/mmwr.mm6629e1.

20. Fantinato FFST, Araújo ELL, Ribeiro IG, Andrade MR, Dantas ALM, Rios JMT, et al. Descrição dos primeiros casos de febre pelo vírus Zika investigados em municípios da região Nordeste do Brasil, 2015. Epidemiol Serv Saúde. 2016 [citado 2017 set 12];25(4):683-90. Disponível em: http://www.scielo.br/pdf/ress/ v25n4/2237-9622-ress-S1679_49742016000400002.pdf.

\section{- Autor correspondente:}

Daniela do Carmo Oliveira Mendes E-mail: danielacarmoliveira@gmail.com
Recebido: 22.02.2018

Aprovado: 02.07.2018 